\title{
EL PESO DEL AIRE
}

Alfredo Núñez Lanz*

\section{Si le sobraba tiempo antes de que} acabara el día, cortaría los aguacates. Vivía en pleito con los pájaros que picoteaban las frutas. Las arrancaba cuando todavía estaban verdes para ganarle también a las plagas que no tardaban en salir. La más común era un extraño terciopelo blanco que crecía alrededor de las hojas, como una barba nudosa e insistente. Era la más fácil de quitar: tomaba la manguera con el dedo en el chorro para desprenderla con potencia, aunque luego quedaran los pelos blancos flotando en todas partes.

Con pura terquedad mantenía lejos los achaques que vienen con los años. No le importaba el peso de aquel garfio oxidado hecho a la medida de las ramas más altas; aunque se le engarrotaran los hombros, seguía alcanzando limones, naranjas o aguacates, lejanos en sus temporadas de brote. Ya después se arrepentía por el dolor en los talones y en los discos de la espalda baja. Pero era su tarea, no podía dejarle ese trabajo al jardinero, que iba cada quince días, porque las frutas se pudrían. Tanto árbol como para dejar los racimos tupidos a la intemperie.

Su jardín y el de los vecinos se empujaban entre sí; las copas de los árboles quedaban abrazándose unas a otras cubiertas de hierba frondosa y parásita. Casi no había partes enteras de suelo donde cayera el sol; se veían garabatos sobre el pasto que temblaba con el siseo del aire. Nadie reclamaba jamás la posesión de las frutas cuando caían de algún

*Editor y escritor. 
lado, se ahorraban la molestia. Ni las bardas habían evitado ese tejido de ramas y hojas. El muro del fondo dividía su jardín del patio de una escuela pública donde también crecía un árbol grueso, alto y de abundante ramaje. Los lunes escuchaba la ceremonia cívica y las voces amplificadas de maestras autoritarias. Algunas aulas habían sido construidas improvisadamente a la altura del muro y por eso los gritos de los niños eran más cercanos desde el jardín.

Aquel día amaneció ansiosa, torpe. Había tenido que lavar dos veces la misma blusa por culpa de manchas grasosas y, por fin, al radio ya no le daba la gana encender, aún moviéndole los cables para todos lados. Dobló sus sábanas y enjuagó los trastes sin escuchar las noticias, sacudió los muebles, barrió y trapeó. En la casa los únicos ruidos que se escuchaban eran los suyos. Demasiado espacio para una mujer sola, pero no tenía a dónde ir $\mathrm{y}$, francamente, las minucias de los bienes raíces la ponían nerviosa. Desde joven se había rehusado a tomar decisiones importantes relacionadas con dinero. Todos esos aspectos incómodos los solucionaba su marido, pero ahora llevaba un año viuda y el silencio había comenzado a preocuparle.

Se las había arreglado muy bien hasta ahora, con la mínima pensión de su esposo. Su única hija vivía con su nieta al otro lado de la ciudad y, como prefería no salir de casa más que para lo necesario, raras veces se reunían. Además, no estaba segura de tener algo en común con ella. A veces pensaba que había heredado todos los rasgos desagradables del padre, como una esponja que absorbe malos olores: desde la joroba en la nariz - culpable de su inseguridad-, hasta la forma de caminar y el modo de hablar rápido y nasal, poniendo siempre un énfasis molesto en las vocales “e” o "i”. Por otro lado, no le gustaba el carácter de su nieta: era malcriada, respondona y hacía lo que se le antojaba. Además, la pequeña se parecía demasiado al padre; tenía su misma mirada ebria.

El reproche más grande que tenía contra su hija se remontaba al nacimiento de su nieta. Insensible a sus consejos de permanecer en cierto reposo, viajó al norte en la última etapa del embarazo para que la niña tuviera nacionalidad extranjera, y no conforme con ello, le había en- 
señado primero a hablar en inglés. Pero su hija la trataba como si fuera la única cosa en el mundo que había que atender, centrando su vida alrededor de la niña. Le resultaba un mal hábito que esa mujer joven, saludable e inteligente, gastara todas sus energías en una actividad tan sencilla e insignificante como construir ese nido, que por otro lado, ya estaba completamente terminado. Los celos y el temor por su hija la volvían un ser práctico, llevando el papel de madre a las más altas cumbres.

Al terminar de colgar la ropa, puso los ojos hacia el aguacate frondoso en actitud cansada y entonces se dijo que tenía que llamar al jardinero. Era demasiada fruta perdida si la dejaba así. Ni modo, tendría que pagar por algo tan sencillo. Luego pensó: "pero si sólo estoy yo, ¿quién comerá?". Sintió que las manos se le enfriaban y antes de que le invadiera esa angustia que llegaba cuando algo ínfimo le exponía su situación de manera tan evidente, brusca y clara, decidió que le llamaría de todos modos. Finalmente ella tenía dinero, aunque modestamente, pero se podía dar ese lujo.

El jardinero era un hombre huesudo, estrecho de hombros, con las sienes hundidas y el pecho plano. Las arrugas del cuello se desdoblaban en pliegues sueltos y cada una de sus canas parecía tener el grueso imposible de un hilo de coser. Ella le preparaba la comida después de sus labores. Una vez no pudo evitar la maldad de ahorrar una semana y prepararle un delicioso salmón para ver la expresión de novedad que ponía. Cuando lo condujo al comedor y por fin se metió a la boca un pedazo, casi ronroneó de placer con la pura actitud de devoción que aquel hombrecillo ponía. Le agradaba la idea de que la respetara.

Marcó el número de memoria. La llamada entró, contestó el hombrecillo y ella expuso el caso con las palabras adecuadas. "Hoy no pude ir a trabajar, tengo gota en el pie, pero mañana paso". Qué vulgaridad tan grande, pensó. No podía haber en el mundo una enfermedad más vulgar que aquélla. Colgó con bastante molestia. En ese momento, el timbre de la puerta sonó. Desde ahí alcanzó a ver la silueta de una mujer que llevaba un mandil. Seguramente sería una vecina con alguna impertinencia. Como era su costumbre, decidió ignorar el timbre y mante- 
nerse en silencio para fingir que no estaba en casa. Ya se enteraría cuando tocara a la casa vecina, a través de los ecos.

"Están preguntando en las otras casas si no vieron a un alumno o alumna de la secundaria en los jardines. No lo encuentran y lo buscaron por toda la escuela. Creen que se saltó la barda para volarse las clases. También te quería preguntar si ya tienen el dinero de la caseta de vigilancia, ya nos deben tres meses...". No alcanzó a escuchar la respuesta de la vecina, pero siguió ahí, atenta y esforzándose para interpretar lo mejor posible. "La cosa está difícil, pero es por nuestra seguridad". "El día quince espero darles todo junto", alcanzó por fin a escuchar la respuesta y recordó que tenía que ser puntual en sus pagos para evitar vergüenzas y deudas.

Miró hacia la sala comedor, todo estaba como ella lo había ordenado. Sus muebles, aunque limpios, tenían marcas evidentes de deterioro, pero no quería deshacerse de nada para impedir gastos. Escribió en su pequeña libreta "pagar vigilancia" abajo del recordatorio del gas y fue directo a la cocina para calentarse las sobras de lo que había preparado el día anterior. No le gustaba comer sola, pero ese detalle quedaba sumido bajo la costumbre diaria. Calentó su comida con cierto nerviosismo, se sirvió moderadamente y, de pronto, le pareció escuchar algunos pasos arriba, en las recámaras. "Pero si estaba sola...", pensó, todavía sin sentarse a la mesa; quizá fuera la madera. Trató de poner el radio para tapar cualquier posible de ruido de casa vieja que la alterara, pero el aparato se negaba a encender como horas antes. Resignada nuevamente al silencio, deseó no haber escuchado nada y se propuso concentrase en comer. Al cabo de un rato, nuevamente comenzaba a crecer esa conciencia de su soledad junto con la angustia. No pudo evitar, entre bocado y bocado, pensar en qué pasaría si le sucediera algo en aquella casa. Nadie está exento de accidentes domésticos ni asaltantes. Ella ya no era una persona joven, empezaría a necesitar de todos tarde o temprano. Aquello la aterraba. Jamás había necesitado de nadie. Odiaba la idea de pedir favores a los vecinos, de ser condescendiente con las personas y convertirse poco a poco en una anciana sonriente y amable, indulgente y comprensiva para que en algún momento la gente le 
pudiera devolver esos favores. Quizá ya no podía conformarse con tener la confianza de los vecinos, sino que ahora debía ir en busca de su cariño en algún momento, apareciéndose en las juntas vecinales.

Volvió a escuchar ruidos. Esta vez con más claridad que antes. No había duda, algo se arrastraba arriba. Subió los escalones con las manos temblando. Para tranquilizarse, pensó que probablemente los culpables eran los ecos guardados en las paredes. No había que preocuparse tanto, recordó las palabras de la vecina y en el peor de los casos, encontraría a un estudiante fumando los puros viejos de su esposo. Los escalones parecían más empinados. Cerró los ojos, no quería ver. Era mejor fingir que no había escuchado nada, creer en la madera inflándose, cediendo a la humedad y vivir con ello de una vez. Se detuvo. Giró el cuerpo para descender. Otra vez los talones se hacían presentes, sobre todo el izquierdo con ese dolor constante. Si un estudiante vago usaba su casa para evadir clases, que la aprovechara. Mientras no la molestara con más quehaceres, le atrajo la idea de estar acompañada y por fin se calmó un poco. Pero habían otras posibilidades. Tal vez la estuvieran asaltando frente a su propia nariz. De sólo imaginar la cara de orgullo de los malditos por la facilidad del robo, volvió a armarse de valor para subir. Sus pasos alertaron al ser o cosa que se arrastraba en la alfombra y se detuvo el sonido. Ahora sabía de dónde provenía y caminó rápido hasta su recámara. Azotó la puerta para intimidar y un maullido resonó como respuesta. Por debajo de su falda corrió el gato responsable.

Dejó escapar un suspiro. Había exagerado como siempre y sólo se trataba de un animal afilándose las uñas. Miró hacia abajo y justo a unos cuantos milímetros de su pie se alzaba un pequeño bulto de excremento orgulloso y triunfante.

Siguió al animal durante horas, persiguiéndolo con una escoba vieja. Abrió las puertas del jardín para que saliera, pero el gato parecía burlarse de ella. Entraba y salía trotando, escalaba los libreros para saltar desde lo más alto y daba vueltas evadiendo la escoba. Había que acorralarlo, pensó agotada. Entonces, el gato bajó por la escalera de servicio y lo encontró bebiéndose el agua de su cubeta con una calma y desfachatez envidiable. Estaba resuelta a correrlo de algún modo, así que deci- 
dió tomar esa misma cubeta y arrojarle el agua puerca. Pero el animal parecía demostrar su agilidad con sorprendentes brincos evasivos. En algún momento comenzó a maldecirlo. Ya entonces la casa había perdido esa apariencia armónica: agua regada por todas partes, cojines tirados y pedazos de platos que habían volado para intentar descalabrarlo.

Por fin logró mantenerlo en el cuarto de servicio a unos cuantos metros de la cocina, pero el animal buscó refugio detrás de la lavadora. Trató de mover el mueble con todas sus fuerzas, pero aquella máquina vieja pesaba demasiado. Metió el palo de la escoba para empujarlo y el gato comenzó a maullar desesperadamente. Notó entonces que estaba atorado entre los cables y los tubos. No había forma de que saliera, porque detrás de aquella lavadora estaba la pared y a un lado se hallaban un montón de cajas con zapatos viejos sobre una televisión inservible. Fue por más agua, pero esta vez decidió calentarla. Quizá la herviría para que viera quién mandaba. Pero la idea de un gato quemado aullando por la noche la hizo retroceder. Tuvo una súbita consideración por el animal asustado: sólo entibiaría el agua para no dañarlo ni provocarle una pulmonía. Preparó rápidamente la cubeta y se dirigió al cuarto de servicio, satisfecha. Arrojó el agua pero el gato no salió. Desesperada, recurrió al aceite de cocina para que pudiera resbalar de dondequiera que estuviera atorado. Pero el animal permanecía allí, aullando y quejándose como un bebé. Corrió por un cigarro de su esposo y lo prendió para arrojarle el humo, quizás así el gato saldría al creer que algo se incendiaba. No resultó.

Agotada, decidió abandonar al animal. Se sentó por un momento en la sala y contempló todo aquel desastre, reviviendo su enojo. ¿Qué otra cosa podía hacer? Miró hacia la pequeña cantina y recordó que conservaba una botella de sidra. Tomó un vaso y comenzó a beber, a nadie le importaba si se emborrachaba. Estaba sola. Salió al jardín y se sentó frente a la mesa de hierro que todavía conservaba trozos con pintura blanca. Ahí, acompañada por los grillos, se bebió toda la botella. La noche era fresca, pero había algo de calidez en el ambiente. El aire traía consigo sonidos lejanos de sirenas. Eran ambulancias, o patrullas. 
Después de varias horas regresó a su habitación y encima de las colchas se quedó dormida. A la mañana siguiente los rayos del sol entraron con fuerza a través de las cortinas. El timbre la despertó. Era el jardinero. Estiró la mano y tiró de la cuerda que movía la cortina. La dureza del hilo fue una agradable sensación contra su mano. La luz pareció inundarla. Los pájaros eran habitualmente ruidosos. Cerca, los gritos de niños comenzaban a sonar y pronto las maestras iniciarían sus órdenes en el altavoz. Quiso al menos cambiarse de ropa, la avergonzaba oler a alcohol delante de un trabajador. Pero decidió recibirlo así. El gato todavía estaba ahí y necesitaba que la ayudaran a sacarlo. Por fin, entre los dos movieron el mueble y el gato salió dando saltos, todavía empapado y brillante de aceite. Corrió directo al jardín. El animal se sentó justo en medio del pasto y los miró. Se quedó inmóvil por un tiempo, observando a sus cazadores. El jardinero dio un paso atrás para volver por sus herramientas dentro de la casa y el gato corrió hacia los árboles del fondo, escalando y perdiéndose entre el follaje.

Las moscas andaban por la mesa de hierro, descendían al vaso con restos aún de sidra, y zumbaban al caer dentro y ahogarse. Arrepentida de todo, pensó en adoptar a ese gato tan pronto bajara de las ramas. Quizá sería una buena compañía y un juguete para la nieta cuando llegara a visitarla. Resignada, caminó hasta donde el sol dejaba de alumbrar entre tanto verdor; se acercó a la parte más lodosa, a unos cuantos metros del muro. El aire siseó natural y trajo con él un crujido pesado justo encima de su cabeza. Miró hacia arriba y ahí estaba ese cuerpo enlazado por el cuello. La joven oscilaba vestida con su uniforme mientras ella estaba de pie ahí, viva, anciana como era. El aire siguió soplando. Un árbol se abrazó a otro. 